\section{P1-118 EXPECTED SOCIO-DEMOGRAPHIC ASSOCIATIONS WITH PROBLEM DRINKING IN RUSSIAN MEN ARE NOT DETECTED USING THE AUDIT OUESTIONNAIRE}

doi:10.1136/jech.2011.142976d.12

S Cook, ${ }^{*}$ B DeStavola, D Leon. London School of Hygiene and Tropical Medicine, London, UK

Introduction Life expectancy in Russia among men is extremely low for an industrialised country (62 years in 2008), which is partly explained by hazardous alcohol consumption. We investigated the relationship between socio-demographic variables and dimensions of alcohol use.

Methods In 2008-2009 a population sample of 996 men aged 2559 years living in Izhevsk, Russia took part in a survey that collected information on socio-demographic circumstances and a selfcompleted questionnaire that included the WHO Alcohol Use Disorders Identification Test (AUDIT). Latent dimensions of the total AUDIT score were determined using confirmatory factor analysis (CFA) and structural equation modelling was used to estimate the strength of association of these dimensions with socio-demographic variables.

Results Confirmatory factor analysis supported a two factor structure for the AUDIT: alcohol consumption and alcohol-related problems. Consumption was highest among men who were unemployed seeking work $(p=0.001)$ but was not related to education $(p=0.91)$ or marital status $(p=0.76)$. The dimension capturing alcohol-related problems was greatest among men who were unemployed seeking work $(p<0.001)$ and those who were less educated $(p=0.02)$ but was not associated with marital status $(p=0.43)$.

Conclusions The main socio-demographic variables available in this study were not associated with the two dimensions of the AUDIT in the same way. This together with the failure to show an association of either AUDIT dimension with marital status is surprising and warrants further investigation. It may indicate limitations in the sensitivity of AUDIT to important aspects of Russian drinking patterns.

\section{P1-119 LOW SOCIAL SUPPORT AS A RISK FACTOR FOR A MAJOR DEPRESSIVE EPISODE IN CANADIAN COMMUNITY- DWELLING SENIORS}

doi:10.1136/jech.2011.142976d.13

\begin{abstract}
${ }^{1} \mathrm{~T}$ Cook, ${ }^{1,2} \mathrm{~J}$ Wang, ${ }^{1} \mathrm{~K}$ Fiest. ${ }^{* 1}$ Department of Community Health Sciences, Faculty of Medicine, University of Calgary, Calgary, Alberta, Canada; ${ }^{2}$ Department of Psychiatry, Faculty of Medicine, University of Calgary, Calgary, Alberta, Canada
\end{abstract}

Background Major depression represents a great cause of disease burden worldwide. Further, the proportion of Canadian citizens aged 65 years of age and older is rapidly growing. Despite this, there is a lack of longitudinal data on risk factors for a major depressive episode in seniors. While current literature has established social support as an important factor in the development and prevention of a major depressive episode, comprehensive measures of social support are rarely employed. A longitudinal approach to examining the relationship between depression and comprehensive social support tools has yet to be conducted in Canada.

Methods This study will use 12 year population-based longitudinal data from the NationalPopulation Health Survey, collected by Statistics Canada The survey will be restricted to individuals aged 65 years of age and older. Demographic and socioeconomic characteristics of the sample will be presented. The 2-year and 10-year incidence proportions of major depression in seniors will be estimated. The cross-sectional and longitudinal association between social support and a major depressive episode will be examined using multivariate logistic regression.

Results This study will meet the thesis requirements for a Master's of Epidemiology. At the time of abstract writing, no results are available for abstract inclusion.Results and conclusions will be available and will be presented at the World Congress of Epidemiology conference in August 2011.

\section{P1-120 WITHDRAWN}

\section{P1-121 WEIGHT CHANGE AND INCIDENCE OF DISABILITY IN ACTIVITIES OF DAILY LIVING IN ELDERLY WOMEN}

doi:10.1136/jech.2011.142976d.14

L P Corona, ${ }^{*}$ T S Alexandre, D P Nunes, J L F Santos, Y A de Oliveira Duarte, M L Lebrao. University of Sao Paulo, São Paulo, Brazil

Introduction Weight change in elderly is known as associated with risk of diseases and mortality.

Objective To examine the association between 2-year weight change and incidence of activities of daily living (ADL) disability in elderly women.

Methods Data comes from a longitudinal survey-SABE Study (Health, Well-being and Ageing), which began in 2000 with a multistage clustered sample of 2143 people aged $\geq 60$ years-old living in Sao Paulo-Brazil. In 2006, during the second wave ( $\mathrm{n}=1115$ re-interviewed), used here as baseline, a subsample of 688 persons aged $\geq 75$ years was followed-up, in 2 rounds (2008-2009). Measures included: Weight change (baseline- 2008); Incidence of $\mathrm{ADL}$ disability (baseline-2009). Logistic regression with ADL status in 2009 as outcome, including health and socioeconomic covariates. Inferences were weighted to account for sample design.

Results In 2006, from 433 women, 227 had no limitation in ADL. In 2009, ADL were analysed in a sample of 162 women. The disability incidence was $171.4 / 1000$ person-years in women who lost more than $5 \%$ of weight, $138.4 / 1000$ person-years in women who gained more than $5 \%$, and $87.4 / 1000$ person-years for women who maintained weight during follow-up. Weight loss was associated to the risk of disability $(\mathrm{OR}=3.38 ; \mathrm{p}=0.012)$, as well as weight gain $(\mathrm{OR}=2.71 ; \mathrm{p}=0.009)$. After adjusting for MMSE score, age, education and frailty, weight gain remained as independent factor associated to disability $(\mathrm{OR}=2.31 ; \mathrm{p}=0.041)$, but weight loss lost significance $(\mathrm{OR}=1.91 ; \mathrm{p}=0.288)$.

Conclusions Weight gain is associated with the risk of developing ADL limitation in older women.

\section{P1-122 FRAILTY AND INCIDENCE OF DISABILITY IN ACTIVITIES OF DAILY LIVING IN ELDERLY}

doi:10.1136/jech.2011.142976d.15

L P Corona, ${ }^{*}$ T S Alexandre, D P Nunes, J L F Santos, Y A de Oliveira Duarte, M L Lebrao. University of Sao Paulo, São Paulo, Brazil

Introduction Frailty is known as a factor associated with risk of disability in elderly.

Objectives To examine the association between frailty status and incidence of activities of daily living (ADL) disability in elderly.

Methods Data comes from a longitudinal survey-SABE (Health, Well-being and Ageing), which began in 2000 with a multistage clustered sample of 2143 people aged $\geq 60$ years-old in Sao PauloBrazil. Frailty components (Fried's model) were included in 2006, during the second wave ( $\mathrm{n}=1115$ re-interviewed). In 2006, used here as baseline, a subsample of 688 persons aged $\geq 75$ years was followed-up, in 2 rounds (2008-2009). Measures included: frailty status in baseline; incidence of ADL disability (baseline-2009). We tested two adjusted logistic multiple regression models. Inferences were weighted to account for sample design.

Results In 2006, 389 elderly had no ADL limitation. In 2009, after excluding those who scored $<19$ in Mini-Mental State Exam, ADL 